\title{
Şanlıurfa İli Çevresinde Yetişen Papatya (Matricaria chamomilla (L.)) Türlerinde Enzim Miktar Tayini
}

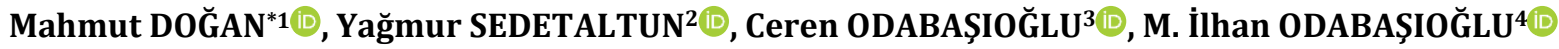 \\ 1,2Harran Üniversitesi, Fen-Edebiyat Fakültesi, Biyoloji Bölümü, 63000, Şanlıurfa, Türkiye \\ ${ }^{3}$ Harran Üniversitesi, Ziraat Fakültesi, Tarla Bitkileri Bölümü, 63000, Şanlıurfa, Türkiye \\ ${ }^{4}$ Harran Üniversitesi, Ziraat Fakültesi, Bahçe Bitkileri Bölümü, 63000, Şanlıurfa, Türkiye
}

(Alınış / Received: 24.12.2020, Kabul / Accepted: 18.05.2021, Online Yayınlanma / Published Online: 15.08.2021)

Anahtar Kelimeler

Şanlıurfa,

Papatya,

Enzim
Özet: Ülkemiz, iklim koşulları açısından papatya bitkisinin doğal olarak yetiştirilmesi için elverişli bir coğrafik konuma sahiptir. Papatya, gerek tıbbi olarak gerek aromatik olarak güncel tedavilerde yoğun olarak kullanılan ve modern tıp tarafından da yoğun olarak ilgi gösterilen bir bitkidir. Halk tıbbında da geniş ve kadim bir kullanımı ve karşılığı olan bu bitki, ülkemizde geniş bir alanda yayılım göstermektedir. $\mathrm{Bu}$ çalıșmamızda tıbbi papatya olarak kullanılan Matricaria chamomilla (L.) bitkisi, 6 farklı bölgeden (Merkez, Siverek, Bozova, Birecik, Halfeti ve Viranșehir) toplanmıș ve klorofil, malondiaaldehit (MDA), prolin, antisiyonin miktarları ile enzim (katalaz, glutatyon redüktaz, askorbat peroksidaz ve süperoksit dismutaz) analizleri yapılmıştır. Analizler toplu olarak değerlendirildiğinde Birecik yöresi örneklerinde katalaz, glutatyon redüktaz ve askorbat peroksidaz enzim aktivite miktarı ile klorofil, prolin ve antosiyaninin en yüksek; süperoksit dismutaz aktivitesinin en az olduğu tespit edilmiştir.

\section{Determination of Enzyme Activity in Chamomile (Matricaria chamomilla (L.)) Species Growing in Sanliurfa Province}

\section{Keywords}

Sanliurfa,

Chamomile,

Enzyme

\begin{abstract}
Our country has a favorable geographical location for naturally growing chamomile plants in terms of climatic conditions. Chamomile is a plant that is use dextensively in current treatments, both medicinally and aromatically, and has shown great interest in modern medicine. This plant, which has a wide and ancient uses and equivalent in folk medicine, is grown in a widearea in our country. In this study, Matricari achamomilla (L.) plant, used as a medicinal chamomile, was collected from 6 different regions (Merkez, Siverek, Bozova, Birecik, Halfeti and Viranșehir), and the amount of chlorophyll, malondiaaldehyde (MDA), proline, antisionine and enzyme (catalase, glutathione reductase, ascorbate peroxidase and superoxide dismutase) analyzes were performed. When the analyzes were evaluated collectively, in the samples of Birecik region it was determined that the amount of catalase, glutathione reductase and ascorbate peroxidase enzyme activity and chlorophyll, proline and anthocyanin were the highest; superoxide dismutase activity was least.
\end{abstract}

\section{Giriş}

Bitkinin bilimsel adı Matricaria chamomilla (L.) olup, bitkinin Türkçe ve yöresel ismi; papatya, çiçek mastık ve yoğurt çiçeğidir. Bitkinin kullanım amacı; teskin edici özelliği nedeniyle bașta bel ve baş ağrısı olmak üzere bölgesel ağrıları dindirmesidir. Bununla birlikte; dişeti ve boğaz iltihaplarının tedavisinde gargara olarak kullanıldığı bilinmektedir. Ayrıca yakacak, boya ve süs amaçlı da kullanımı söz konusudur.

Papatya bitkisinin anavatanı Doğu Avrupa ve Asya'dır. Ancak geçtiğimiz birkaç yüzyıldan bu yana
Orta Avrupa'ya da yayılmıstır. Amerika ve Avustralya'ya ise tahıllarla beraber götürülmüștür. Chamaemelon adı altında Plinius ve Dioskorides (M.S. 77-79) tarafından, aynı zamanda Arap tabipler tarafından da kullanılmıştır. Erken dönemlerde, papatya çiçeklerinden elde edilen yağdan hazırlanan preparatların kullanıldığı belirtilmektedir. Günümüzde bile mavi yağ olarak bilinen papatya yağından, ilk defa 1588'de bahsedilmiştir. Mayıs papatyası bugün dünyanın birçok yöresine yayılmış bulunmakta ve pek çok ülkede kültürü yapılmaktadır. En fazla üretimi yapılan ülkeler Almanya, Macaristan, Rusya, Belçika, Fransa, İspanya, Yunanistan ve Türkiye'dir [1-3]. 
Papatya bitkisi, Papatyagiller (Asteraceae) ailesindendir. Yaklaşık 25 santim boyunda, bir yıllık ve otsu yapıda bir bitkidir. Yaprakları ince parçalı olup, yaprak sapı yoktur. Çiçeğinin orta kısmı sarı veya sarının farklı tonlarındadır. Meyvesinden sarımsı-esmer renkli uçucu yağ elde edilir. Mevcut uçucu yağlar içinde en yumuşak olanlardan biridir. Öksürük ve bronşitte, boğmacada, cilt iltihaplarında, kaşıntıda, sivilcede, zona hastalığında, yarık ve çatlak deride, sinirsel kaynaklı kas kasılmalarında, çocuklarda uyku bozukluklarında, çocuklarda sinirsel karın ağrılarında, korkularda sakinleștirici, rahatlatıcl, stres giderici, iltihap ve kramp önleyici, anti bakteriyel, mantar önleyici, antiviral, yaraları iyileştirmeye hızlandırıcı, ağrı hafifletici ve cilt bakımına yardımcı olarak kullanılmaktadır $[4,5]$. Mayıs-Ağustos aylarında yetişen, hoş kokulu, tek yıllık bir bitki olan papatya; otoyol kenarları, rekreasyon alanları, tarlalar, bahçeler vb. kısacası boş bulduğu her alanda yetişebilmektedir [2, 3].

Ülkemiz zengin bir biyoçeşitliliğe sahiptir. Bu zenginlik ülkemize özgü endemik bitkilerin çeşitliliğini de beraberinde getirmektedir. Avrupa'nın tamamında 13000 adet farklı bitki türü varken yalnızca ülkemizde bu değer 12000 civarındadır. Ülkemizde 346 adet bitkinin ticareti yapılmaktadır. $\mathrm{Bu}$ bitkilerden 112 adet tür ihraç edilerek ülkemiz ekonomisine katkı sağlamaktadır. İhraç edilen bu bitkilerin 24 adetinin endemik bitki olduğu bildirilmektedir [6-8].

İnsanların bitkilere olan ilgisi ve onlarla ilişkisi insanlık tarihi kadar eskidir. Nitekim beslenme ihtiyacının karşılanması dışında da insanlar bitkilerle ilgilenmiș ve onları çeșitli hastalıkların tedavisinde de kullanmışlardır. Bu sayede; insanlık tarihi boyunca nesilden nesle aktarlan deneyim ve tedavi yöntemleri, belirli bir birikim oluşturmuştur. Günümüzde, Dünya Sağlık Örgütü (WHO); bitkisel drogların sayısını 1900 olarak belirlemiștir. Bununla birlikte; dünyada, tedavi sürecinde yararlanılan yaklaşık 20.000 bitkinin 600 kadarı Türkiye'de yetişmektedir [9]. Hem bitkilerin sayısının çokluğu hem de çeşitliliği; bunlara ait bilgilerin düzenli bir şekilde yazılı hale getirilmesini zorunlu kılmaktadır. Son ylllarda, bu alanda; Hindistan, Çin, Nijerya, Kenya ve Latin Amerika ülkelerinin atılım yaptıkları görülmektedir. Söz konusu ülkelerde, etnobotanik üzerine enstitüler ve laboratuvarlar da kurulmuștur. Türk toplumunda çoğunluğun kırsal bölgelerde yaşamasından dolayı halk, yabani bitkilerle yakından ilgilenmektedir. Halk yabani bitkilerin bir bölümünden gıda, baharat, boyar madde veya hastalıkların tedavisinde yararlanmaktadır. Tıbbî bitkilerden en üst düzeyde istifade edebilmek, amaca uygun üretimini ve kullanımını sağlamak, tedavi sürecindeki etkinliklerini arttırmak için; kimyasal içeriğinin ve etken maddelerinin miktarları, özellikleri ve etki mekanizmalarının tespit edilmesi gerekmektedir [10-13].
Güneydoğu Anadolu Bölgesi'nin tıbbî folkloru; özellikle bu bölgedeki pek çok yerleşim yerinin geniş bir coğrafyaya dağınık halde ve büyük ölçüde korunmuş olması sebebiyle önem arz etmektedir. Bölgede kültürü yapılan birçok bitki türü ve bazı yabani türler, tedavi edici özelliğiyle bilinmektedir. Gerek sanayi yatırımlarının gecikmesi gerekse ulaşım olanaklarının uzun yıllar boyunca sinırlı kalması nedeniyle, bu bölgede yüzlerce yıldan bu yana sürdürülen geleneklerin çoğu değişmeden günümüze dek gelebilmiştir. Bu geleneklerden biri olan, tedavi edici özellikleriyle bilinen bitkilerin kullanımı; kırsal kesimde olduğu kadar, kent yaşamı içinde de yerini almıştır [14-17].

$\mathrm{Bu}$ çalıșmada tıbbi papatya olarak kullanılan Matricaria chamomilla (L.) bitkisinin, 6 farklı bölgeden (Merkez, Siverek, Bozova, Birecik, Halfeti ve Viranşehir) toplanan bitki örneklerinde enzim miktarı bakımından analizini yapmak, literatürde papatya ile ilgili eksiklerin giderilmesine katkı sunmak, sıkça kullanılan bu bitki hakkında genel bilgiler ve sonuçlar elde etmek amaçlanmıştır.

\section{Materyal ve Metot}

Çalışmamızda 6 farklı yöreden (Merkez, Siverek, Bozova, Birecik, Halfeti ve Viranșehir) toplanan papatya örneklerinin yaprakları ve dalları (homojenize edilerek) kullanılmıştır. Toplanan bitki örnekleri laboratuvar ortamında analize hazır hale getirilerek, klorofil, malondiaaldehit (MDA), prolin, antisiyonin miktarları ve enzim (Katalaz (CAT), Gulutatyon redüktaz (GR), Askorbat peroksidaz (APX), Süperoksit dismutaz (SOD) aktiviteleri belirlenmiştir.

Klorofil miktarı; Luna ve ark. [18], yöntemine göre gerçekleştirilmiştir. Papatya örnekleri \%80 oranında $10 \mathrm{~mL}$ etanol içerisine koyulmuştur. $80^{\circ} \mathrm{C}$ sıcaklıkta 20 dakika inkübasyona bırakılmıştır. Daha sonra örnekler 5000 rpm devirle 10 dakika santrifüj edilmiştir. Ardından; $654 \mathrm{~nm}$ absorbans değeri ile spektrofotometrede (Shimadzu UV-1208) okunmuştur. Sonuçlar $\mu \mathrm{g} / \mathrm{mg}$ taze ağırlık (T.A.) olarak hesaplanmıştır.

MDA miktarı; Lutts ve ark. [19], yöntemine göre çalışılmıştır. Papatya örneklerinden 200 mg yaprak tartılıp alınarak \%0.1 'lik $5 \mathrm{~mL}$ trichloro acetic acid (TCA) eklenmiștir. Hazırlanan bu karıșım 20 dakika $12500 \mathrm{rpm}$ devirle santrifüj edilmiștir. Bu ekstrakttan 3mL süpernatant alınıp içerisine \%20 thiobarbituric acid (TBA) bulunan \%0.1 'lik 3mL TCA eklenmiştir. Karışım, $95{ }^{\circ} \mathrm{C}$ sıcaklıktaki su banyosunda 30 dakika bekletildikten sonra spektrofotometrede (Shimadzu UV-1208) 532 ile 600 nm absorbans değerlerinde okuma yapılmıştır. Kör olarak \%0.1'lik \%20 TBA barındıran TCA kullanılmıştır. 
Prolin miktarı; Bates ve ark. [20]' nın geliştirdiği yöntemle yapılmıştır. Yönteme göre; $0.5 \mathrm{~g}$ yaş yaprak örneği \%3'lük Sulfosalisik asit (10 mL) ile homojenize edilmiştir. Filtre edilen örnekler 60 dakika boyunca $90{ }^{\circ} \mathrm{C}^{\prime} \mathrm{de}$ su banyosu içerisinde ninhidrin ile reaksiyona sokulmuştur. Ardından örnekler buz banyosuna alınmış ve reaksiyon tamamlanmıștır. Soğutulmadan sonra ortam toulen ile ekstrakte edilmiş ve pembemsi-kırmızı renkte, standart olarak L prolin kullanılarak $520 \mathrm{~nm}$ ' de spektrofotometrede okuma yapılmıştır. Sonuçlar ( $\mu \mathrm{mol} / \mathrm{g}$ T.A.) olarak hesaplanmıştır.

Antosiyanin miktarı; Fuleki ve Francis [21] tarafından geliştirilmiş bulunan $\mathrm{pH}$-diferansiyel tayin metoduna göre saptanmıștır. Antosiyanin maksimum absorbansı 520-700 $\mathrm{nm}$ arası olduğundan $610 \mathrm{~nm}$ dalga boyunda spektrofotometrede okunmuştur. Tüm stok süresince, konsantre örnekleri aynı seyreltme oranlarına uyularak seyreltilmiş ve böylece analizler spektrofotometrenin linear sinırı olan 1.2 absorbans değerinin altında yürütülmüștür [22]. Potasyum klorür çözeltisi (pH:1) ile belirlenen bu seyreltme oranı hem potasyum klorür ve hem de sodyum asetat tampon çözeltisi (pH:4.5) ile uygulanmış ve elde edilen seyreltikler, 15 dakika süre ile denge oluşması için bekletilmişlerdir. Daha sonra, süpernatant whatman no:1 filtre kağıdından filtre edilmiş ve örnek ile körün (\%0.01'lik $\mathrm{HCl})$ aynı anda koyulabildiği çift hazneli spektrofotometre kullanılarak saptanmıştır. Antosiyanin miktarı bütün örneklerde, siyanidin 3-glikozit cinsinden 34 (MW=445,2 mol absorbans, $\varepsilon=29.600$ ) hesaplanmıştır $[23,24]$.

Enzim aktivitelerinin belirlenmesi ve ekstraktların hazırlanmasında ise; Papatya bitkisinden alınan $0.5 \mathrm{~g}$ yaş yaprak örneğine sıvı azot eklenerek, porselen havan içerisinde ezilmiştir. Ezilen yaprak örnekleri, içerisinde $0.1 \mathrm{mM}$ Na-EDTA bulunan $50 \mathrm{mM}^{\prime}$ lık (pH7.6) fosfat (P) tampon çözeltisi ile $(10 \mathrm{~mL})$ homojenize edilmiştir. Homojenize edilen örnekler 15 dakika boyunca $15000 \mathrm{rpm}$ ve $+4{ }^{\circ} \mathrm{C}$ 'de santrifüjlendikten sonra, elde edilen süpernatantta enzim aktiviteleri; Çakmak, ve Marschner [25] ile Çakmak [26]'ın bildirdikleri yöntemlere göre belirlenmiștir.
Çalışma 3 yinelemeli olarak yürütülmüş ve her bir yinelemede 3 adet örnek (toplam 144 örnek) kullanılmıştır. Tesadüf parselleri deneme deseninde 3 yinelemeli varyans analizi bakımından faktörler incelenmiştir. Papatya örnekleri arasındaki farklar anlamlı önemli fark (A.Ö.F.) çoklu karşılaştırma yöntemiyle incelenmiştir.

\section{Bulgular ve Tartışma}

Farklı bölgelerden toplanan papatya örneklerinde yapılan analizlere ilişkin sonuçlar, Tablo 1 ve Tablo 2'de sunulmuştur. Varyans analizi bakımından klorofil, MDA, prolin ve antosiyanin enzim miktarları ile pozitif yönde anlamlı ve birbirleriyle ilişkili bulunmuştur $(\mathrm{P}<0.5)$. Özellikle klorofil, MDA, prolin ve antosiyaninin bütün enzimlerle anlamlı olması önemli bir gösterge olarak kabul edilmektedir [27, 28].

Parametrelerin tek başına yüksek olması kayda değer önemli bir parametre olarak kabul görmemektedir [29]. Ancak parametrelerin birbirlerini destekler nitelikte yüksek olması önemli bir anlam ifade etmektedir [30, 31]. Enzim parametreleri bakımından bakıldığında klorofil ile pozitif yönde ilișkili olması, klorofil parametrelerinin bu enzimleri desteklemesi olumlu bir gösterge olarak değerlendirilmektedir [30, 31]. Enzim ve klorofil miktarlarının yüksek olması arasındaki ilişkiye göre anlam ifade etmektedir Torun ve Ayaz [32] ile Kendall, ve Mckersie [33] 'nin bildirdiğine göre; bitkilerin stres koşullarında ürettikleri aktif $\mathrm{O}^{2}$ radikalleri membranlarda lipid peroksidasyonuna neden olmakta ve buna bağlı olarak membranlarin hasarlanmasiyla sonuçlanmaktadır. MDA değerlerinin yüksek olması; papatyanın, diğer bitki türlerinde de olduğu gibi çevresel stres etkenlerinden etkilenebileceğini ve serbest radikal oluşumunun stres koşullarında önemli düzeyde artabileceğini ortaya koymaktadır.

Elde edilen veriler toplu olarak değerlendirildiğinde Birecik yöresine ait örneklerde klorofil $0.188 \pm 2$, prolin 1,880 \pm 3 , antosiyanin 2,87 $\pm 1 \mu \mathrm{g} / \mathrm{mg}$ T.A. miktarıyla en yüksek bulunurken MDA 0,328 \pm 3 $\mu \mathrm{g} / \mathrm{mg}$ T.A. miktarıyla en düşük bulunmuştur.

Tablo 1. Farklı 6 bölgeden toplanan papatya örneklerinde klorofil, MDA, prolin ve antosiyanin analiz sonuçları. (Değerler üç yinelemenin ortalaması \pm standart hata olarak verilmiştir)

\begin{tabular}{ccccc}
\hline İstasyon & $\begin{array}{c}\text { Klorofil } \\
(\mu \mathrm{g} / \mathrm{mg} \text { T.A. })\end{array}$ & $\begin{array}{c}\text { MDA } \\
(\mu \mathrm{g} / \mathrm{mg} \text { T.A. })\end{array}$ & $\begin{array}{c}\text { Prolin } \\
(\mu \mathrm{mol} / \mathrm{g} \text { T.A. })\end{array}$ & $\begin{array}{c}\text { Antosiyanin } \\
(\mu \mathrm{g} / \mathrm{mg} \text { T.A. })\end{array}$ \\
\hline Merkez & $0.173 \pm 1 \mathrm{a}$ & $0,549 \pm 3 \mathrm{bc}$ & $0,954 \pm 4 \mathrm{a}$ & $2,80 \pm 2 \mathrm{~b}$ \\
Siverek & $0.176 \pm 1 \mathrm{a}$ & $0,572 \pm 1 \mathrm{bc}$ & $1,484 \pm 2 \mathrm{~b}$ & $2,38 \pm 2 \mathrm{a}$ \\
Bozova & $0.188 \pm 2 \mathrm{~b}$ & $0,551 \pm 2 \mathrm{~b}$ & $1,595 \pm 3 \mathrm{~b}$ & $2,75 \pm 3 \mathrm{a}$ \\
Birecik & $0.198 \pm 3 \mathrm{bc}$ & $0,328 \pm 3 \mathrm{a}$ & $1,880 \pm 3 \mathrm{bc}$ & $2,87 \pm 1 \mathrm{~b}$ \\
Halfeti & $0.184 \pm 2 \mathrm{~b}$ & $0,508 \pm 3 \mathrm{~b}$ & $1,632 \pm 3 \mathrm{c}$ & $2,80 \pm 2 \mathrm{~b}$ \\
Viranșehir & $0.196 \pm 1 \mathrm{bc}$ & $0,443 \pm 3 \mathrm{a}$ & $1,856 \pm 3 \mathrm{bc}$ & $2,51 \pm 3 \mathrm{a}$ \\
\hline
\end{tabular}

Klorofil $p=0.025$, MDA $p=0.044$, Prolin $=0.062$, Antosiyanin $\mathrm{P}=0.078$ 
Tablo 2. Farklı 6 bölgeden toplanan papatya örneklerinde CAT, GR, APX ve SOD analiz sonuçları. (Değerler üç yinelemenin ortalaması \pm standart hata olarak verilmiştir).

\begin{tabular}{|c|c|c|c|c|}
\hline İstasyon & $\begin{array}{c}\text { CAT } \\
(\mu \mathrm{mol} / \mathrm{g} \text { T.A Dak.) }\end{array}$ & $\begin{array}{c}\text { GR } \\
(\mu \mathrm{mol} / \mathrm{g} \text { T.A Dak. })\end{array}$ & $\begin{array}{c}\text { APX } \\
(\mu \mathrm{mol} / \mathrm{g} \text { T.A Dak. })\end{array}$ & $\begin{array}{c}\text { SOD } \\
\text { (Unite/g T.A) }\end{array}$ \\
\hline Merkez & $7.3 \pm 2 b$ & $42.2 \pm 2 \mathrm{a}$ & $6.2 \pm 1 \mathrm{a}$ & $904 \pm 1 c$ \\
\hline Siverek & $6.4 \pm 3 a$ & $55.4 \pm 3 b$ & $6.4 \pm 3 a$ & $897 \pm 2 b$ \\
\hline Bozova & $7.2 \pm 1 b$ & $51.6 \pm 3 b$ & $6.5 \pm 3 a$ & $831 \pm 3 a$ \\
\hline Birecik & $7.7 \pm 2 b$ & $59.4 \pm 2 b$ & $7.6 \pm 3 b$ & $821 \pm 2 a$ \\
\hline Halfeti & $6.7 \pm 2 a$ & $48.9 \pm 3 a$ & $6.3 \pm 2 a$ & $846 \pm 3 b$ \\
\hline Viranşehir & $6.2 \pm 3 a$ & $56.2 \pm 3 b$ & $6.4 \pm 1 \mathrm{a}$ & $832 \pm 3 a$ \\
\hline
\end{tabular}

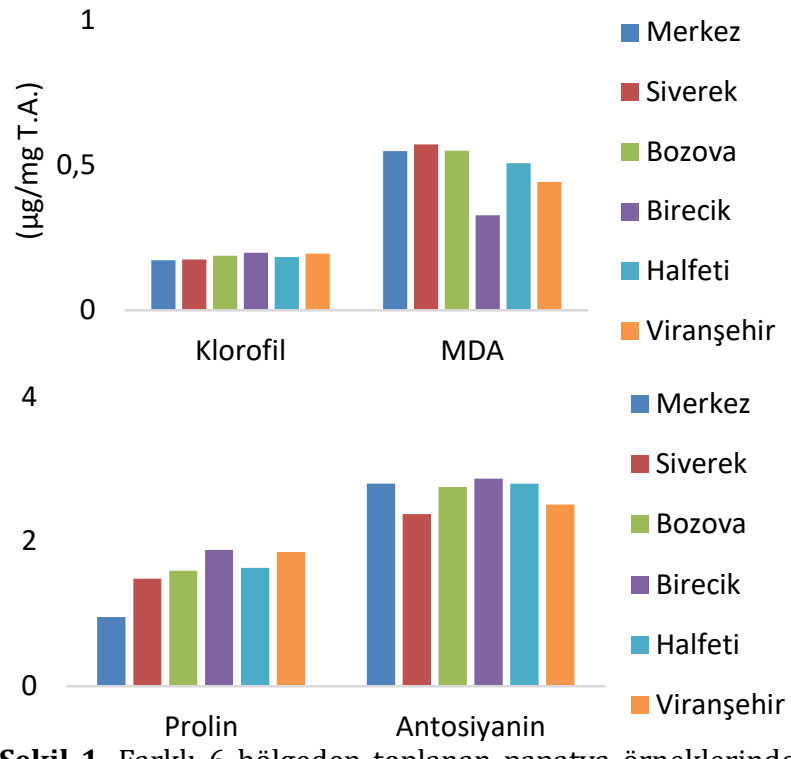

Şekil 1. Farklı 6 bölgeden toplanan papatya örneklerinde klorofil, MDA, prolin ve antosiyanin analiz sonuçları

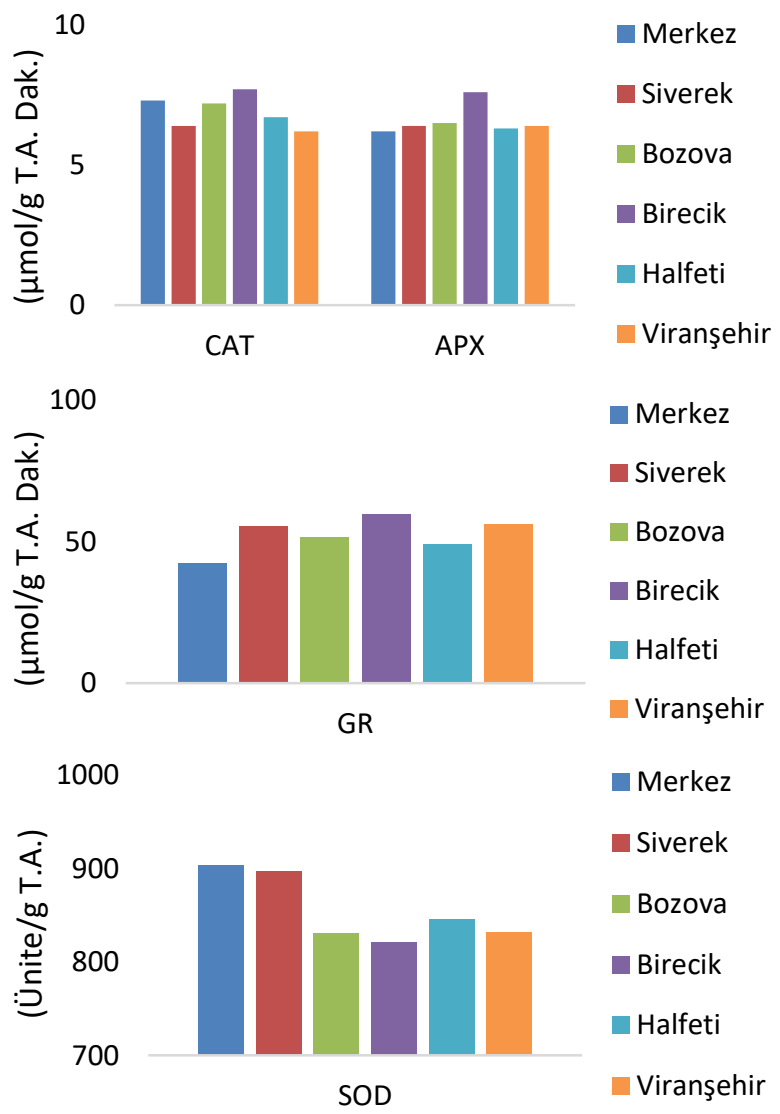

Şekil 2. Farklı 6 bölgeden toplanan papatya örneklerinde CAT, APX, GR ve SOD analiz sonuçları
Hücre hasarının bir göstergesi olan malondialdehidin (MDA), Birecik'ten alınan örneklerde düșük bulunması olumlu ve önemli bir gösterge olarak kabul edilmiştir. Enzim miktarları bakımından sonuçlar değerlendirildiğinde; Katalaz (CAT) 7.7 \pm 2 , Glutatyon redüktaz (GR) 59.4 \pm 2 , Askorbat peroksidaz (APX) 7.6 $\pm 3 \mu \mathrm{mol} / \mathrm{g}$ T.A dk. miktarl, Birecik yöresinde en yüksek bulunurken, Süperoksit dismutaz (SOD) 821 2 Ünite/g T.A ise en düşük bulunmuştur. CAT, GR ve APX in yüksek bulunması, SOD' un düşük bulunması önemli bir parametre ve olumlu olarak değerlendirilmiştir.

Birecik yöresinde klorofil, prolin ve antosiyanin'in yüksek olması, CAT, GR ve APX tarafından yüksek miktarda desteklenmesi, bu yörede bulunan papatya için olumlu bir göstergedir.

\section{Sonuç}

Ülkemiz, farklı ekolojik özellikler gösteren birçok bölgeye sahip olması sayesinde; papatya bitkisinin hem doğal yetişmesi hem de kültürünün yapılabilmesi için oldukça elverişli bir konuma sahiptir. Enzim ve diğer parametreler birlikte değerlendirildiğinde, daha önce papatya bitkisi üzerinde bu denli kapsamlı bir çalışma yapılmamış olup, bundan sonra yapılacak çalışmalara kaynak oluşturması bakımından literatüre katkı sağlayacağı düşünülmektedir. Bütün parametreler birlikte değerlendirildiğinde pozitif yönde anlamlı ilişkiler tespit edilmiştir. 6 farklı yöreden toplanan papatya örneklerinde enzim ve diğer parametrelerin miktarı Birecik yöresinde en yüksek olduğu anlaşılmıştır.

\section{Etik Beyanı}

Bu çalışmada, "Yükseköğretim Kurumları Bilimsel Araştırma ve Yayın Etiği Yönergesi” kapsamında uyulması gerekli tüm kurallara uyulduğunu, bahsi geçen yönergenin "Bilimsel Araştırma ve Yayın Etiğine Aykırı Eylemler" başlığı altında belirtilen eylemlerden hiçbirinin gerçekleştirilmediğini taahhüt ederiz.

\section{Kaynakça}

[1] Çalikoğlu, E., Kıralan, M., Bayrak, A. 2006. Uçucu yağ nedir, nasıl üretilir ve Türkiye'deki durumuna genel bir bakış. Türkiye 9. Gıda 
Kongresi Bildiriler Kitabı, 24-26 Mayıs, Bolu, 569-570.

[2] Arslan, D. 2012. Yalova ekolojik koşullarında mayıs papatyası (Matricaria recutita L.) çeşitlerinde farklı ekim zamanları ve ekim mesafelerinin verim ve kalite özelliklerine etkisi, Ege üniversitesi, Fen Bilimleri Enstitüsü, Doktora Tezi, 175s, İzmir.

[3] Amıragaı, M. E., Koç, A. 2016. Ekim Zamanı ve Azot Uygulamalarının Mayıs Papatyasının (Matricariac hamomilla L.) Verim ve Uçucu Yağ Üretimine Etkileri. Atatürk Üniversitesi Ziraat Fakültesi Dergisi, 47 (1): 31-34.

[4] Haşimi, N., Kızıl, S., Tolan, V. 2015. Rezene ve Adaçayı Uçucu Yağlarının Anti mikrobiyal aktivitesi üzerine bir araștırma. Batman Üniversitesi Yaşam Bilimleri Dergisi, 5(2), 22735.

[5] İlkimen, H., Gülbandılar, A. 2018. Lavanta, ada çayı, kekik ve papatya ekstrelerinin anti mikrobiyal etkilerinin araştırılması. Türk Mikrobiyol Cemiyeti Dergisi, 48(4), 241-246.

[6] Ren, W., Qiao, Z., Wang, H., Zhu, L., Zhang, L. 2003. Flavonoids: promising anticancer agents. Medicinal Research Reviews, 23, 519-34.

[7] Yiğit, N., Benli, M. 2005. Ülkemizde yaygın kullanımı olan kekik (Thymus vulgaris) bitkisinin anti mikrobiyal aktivitesi. Orlab On-Line Mikrobiyoloji Dergisi, 3(8), 1-8.

[8] Hussain, T., Arshad, M., Khan, S., Satar, H., Qureshi, M. S. 2011. In vitros creening of methanol plant extracts for their antibacterial activity. Pakistan Journal of Botany, 43, 531-538.

[9] Kaya, D., Ergönül, P. G. 2015. Obtaining methods of volatileoils. GIDA-Journal of Food, 40(5), 303310.

[10] Jackson, F. 1993. Antihelmintic resistancethestate of play. British Veterinary Journal, $149(2), 123-138$.

[11] Kırbağ, S., Bağcı, E. 2000. Picea abies (L.) Karst. ve Picea orientalis (L.) link uçucu yağlarının antimikrobiyal aktivitesi üzerine bir araştırma, Journal of Qafqaz University, 3(1), 183-190.

[12] Dash, B. K., Sultana, S., Sultana, N. 2011. Antibacterial activities of methanol and acetone extracts of fenugreek (Trigonella foenum) and coriander (Coriandrum sativum). International Journal of Life Science and Medical Research, 27, 1-8.

[13] Shanthi, Sree, K. S., Yasodamma, N., Parama Geetham, C. H. 2010. Phytoc hemical screening and in vitro antibacterial activity of the methanolic leaf extract: sebastianiac hamaelea müell arg. The Bioscan, 5, 173-175.
[14] İlhan, A., Gürel, A., Armutçu, F., Kamışlı, S., İraz, M. 2005. Antiepileptogenic and antioxidant effects of nigellasativa oil against pentylenetetrazol-inducedkindling in mice. Neuro pharmacology, 49(4), 456-464.

[15] Kırbağ S., Zengin, F. 2006. Elazı̆̆ yöresindeki bazı tıbbi bitkilerin antimikrobiyal aktiviteleri. Yüzüncü Yıl Üniversitesi Ziraat Fakültesi Tarım Bilimleri Dergisi, 16(2), 77-80.

[16] Erecevit, P. 2007. Tıbbi amaçlar için kullanılan bazı bitki türlerinin antimikrobiyal aktivitelerinin araştırılması. Yüksek Lisans Tezi, Fırat Üniversitesi, Fen Bilimleri Enstitüsü, 30s. Elazı̆̆.

[17] Kırca, A., Bilișli, A., Demirel, N. N., Turhan, H., Arslan, E. 2007. Çanakkale florasındaki bazı tıbbi ve aromatik bitkilerin antioksidan ve antimikrobiyal aktiviteleri. TÜBİTAK Proje No: 1040292.

[18] Luna, C., Seffino, L. G., Arias, C., Taleisnik, E. 2000. Oxidative stres indicators as selection tools for salt tolerance in chlorisgayana. Plant Breeding, 119, 341-345.

[19] Lutts, S., Kinet, J. M., Bouharmont, J. 1996. NaClinduced senesence in leaves of rice (Oryza sativa L.) cultivars differing in salinity resistance. Annals of Botany, 78, 389-398.

[20] Bates, L. S., Waldren, R. P., Teare, I. D. 1973. Rapid determination of free proline for waterstres studies. Plant and Soil, 39, 205-207.

[21] Fuleki, T., Francis, F. J. 1968. Quantitative methods for anthocyanins. II. determination of total anthocyaninand degradation index for cranberry juice. Journal of Food Science, 33, 7883.

[22] Cemeroğlu B. 2007. Gıda analizleri. Gıda Teknolojisi Derneği Yayınları, No:34, 535s, Ankara.

[23] Alasalvar, C., Bolling, B. W. 2015. Review of nut phytochemicals, fat-soluble bioactives, antioxidant components and health effects. British Journal of Nutrition, 113(S2), 68-78.

[24] Wrolstad R. E. 1976. Color and pigment analysis in fruit products. Oregon Agricultural Experiment Station Bulletin, No:264, 17 s.

[25] Çakmak, I., Marschner, H. 1992. Magnesium Defficiency and Highlight Intensity Enhance Activities of Superoxide Dismutase, Ascorbate Peroxidase and Glutathione Reductase in BeanLeaves, Plant Physiol., 98, 1222-1226.

[26] Çakmak, I. 1994. Activity of ascorbatedependent $\mathrm{H}_{2} \mathrm{O}_{2}$-scaveninig enzymes and leaf shlorosisare enhanced in magnesium and potassium-deficient leaves but not in 
phosphorus-deficient leaves. Journal of Experimental Botany, 45, 1259-1266.

[27] Mittova, V., Tal, M., Volokitta, M., Guy, M. 2002. Salt stres inducesup-regulation of an efficient chloroplast antioxidant system in the salttolerant wild tomato species Lycopersicon pennellii but not in the cultivated species. Physiologia Pantarum, 115, 393-400.

[28] Mittova, V., Guy, M., Tal, M., Volokita, M. 2004. Salinity up-regulates the antioxidative system in root mitochondria and Peroxisomes of the wild salt-tolerant tomato species Lycopersicon pennellii. Journal of Experimental Botany, 55, 1105- 1113.

[29] Mittova, V., Volokita, M., Guy, M., Tal, M. 2000. Activities of SOD and the ascorbate-glutathione cycle enzymes in subcellular compartments in leaves and roots of the cultivated tomato and its wild salt-tolerant relative Lycopersicon pennelli. Physiologia Plantarum, 110, 42-51.
[30] Jaleel, C. A., Gopi R., Manivannah, P., Panneerselvam, R. 2007. Antioxidative potentials as a protective mechanism in Catharanthus rosaus (L.) G. Don. plants under salinity stress. Turkish Journal of Botany, 31, 248-251.

[31] Doğan, M. 2011. Antioxidative and proline potentials as a protective mechanism in soybean plants under salinity stres. Journal of Biotechnology, 10(32), 5972-5978.

[32] Torun, H., Ayaz, F. A. 2019. Tuz stresi koşullarında salisilik asidin zamana bağlı uygulamasının arpa (Hordeum vulgare L.) köklerinin antioksidan savunma sistemleri üzerine etkileri. Eskişehir Teknik Üniversitesi Bilim ve Teknoloji Dergisi Yaşam Bilimleri ve Biyoteknoloji, 8(1), $69-84$.

[33] Kendall, E. J., Mckersie, B. D. 1989. Free radical and freezing injuryto cell membranes of winter what. Plant Physiology, 76, 86-94. 